\title{
The Formation of Oxytocin Dimers is Suppressed by the Zinc-Aspartate-Oxytocin Complex
}

\author{
CHRISTINA AVANTI, ${ }^{1,2}$ WOUTER L.J. HINRICHS, ${ }^{2}$ ANGELA CASINI ${ }^{3}$ ANKO C. EISSENS, ${ }^{2}$ ANNIE VAN DAM, ${ }^{4}$ ALEXEJ KEDROV, \\ ARNOLD J. M. DRIESSEN, ${ }^{5}$ HENDERIK W. FRIJLINK, ${ }^{2}$ HJALMAR P. PERMENTIER ${ }^{4}$ \\ ${ }^{1}$ Department of Pharmaceutics, Faculty of Pharmacy, University of Surabaya (Ubaya), Surabaya, Indonesia \\ ${ }^{2}$ Department of Pharmaceutical Technology and Biopharmacy, University of Groningen, Groningen, The Netherlands \\ ${ }^{3}$ Pharmacokinetics, Toxicology and Targeting, Research Institute of Pharmacy, University of Groningen, Groningen, The Netherlands \\ ${ }^{4}$ Mass Spectrometry Core Facility, University of Groningen, Groningen, The Netherlands \\ ${ }^{5}$ Department of Molecular Microbiology, University of Groningen, Groningen, The Netherlands
}

Received 22 January 2013; revised 21 March 2013; accepted 27 March 2013

Published online 15 April 2013 in Wiley Online Library (wileyonlinelibrary.com). DOI 10.1002/jps.23546

\begin{abstract}
The aim of this study was to investigate the effect of divalent metal ions $(\mathrm{Ca}$, $\mathrm{Mg}^{2+}$, and $\mathrm{Zn}^{2+}$ ) on the stability of oxytocin in aspartate buffer ( $\mathrm{pH} 4.5$ ) and to determine their interaction with the peptide in aqueous solution. Reversed-phase high-performance liquid chromatography and high-performance size-exclusion chromatography measurements indicated that after 4 weeks of storage at $55^{\circ} \mathrm{C}$, all tested divalent metal ions improved the stability of oxytocin in aspartate-buffered solutions ( $\mathrm{pH} 4.5$ ). However, the stabilizing effects of $\mathrm{Zn}^{2+}$ were by far superior compared with $\mathrm{Ca}^{2+}$ and $\mathrm{Mg}^{2+}$. Liquid chromatography-tandem mass spectrometry showed that the combination of aspartate and $\mathrm{Zn}^{2+}$ in particular suppressed the formation of peptide dimers. As shown by isothermal titration calorimetry, $\mathrm{Zn}^{2+}$ interacted with oxytocin in the presence of aspartate buffer, whereas $\mathrm{Ca}^{2+}$ or $\mathrm{Mg}^{2+}$ did not. In conclusion, the stability of oxytocin in the aspartate-buffered solution is strongly improved in the presence of $\mathrm{Zn}^{2+}$, and the stabilization effect is correlated with the ability of the divalent metal ions in aspartate buffer to interact with oxytocin. The reported results are discussed in relation to the possible mode of interactions among the peptide, $\mathrm{Zn}^{2+}$, and buffer components leading to the observed stabilization effects. (C) 2013 Wiley Periodicals, Inc. and the American Pharmacists Association J Pharm Sci 102:1734-1741, 2013
\end{abstract}

Keywords: stability; oxytocin; zinc ions; aspartate buffer; aqueous; formulation; peptide; degradation; kinetic

\section{INTRODUCTION}

Pregnant women may face life-threatening blood loss at the time of delivery. As stated in the International Confederation of Midwives (ICM) - International Federation of Gynecologists and Obstetricians (FIGO) joint statement, the drug of choice to prevent bleeding after child birth (postpartum hemorrhage) is oxytocin. ${ }^{1}$ Oxytocin (Fig. 1) is a nonapeptide hormone that is composed of a cyclic sequence of

Additional Supporting Information may be found in the online version of this article. Supporting Information

Correspondence to: Christina Avanti (Telephone: +62-312981110; Fax: +62-31-2981111; E-mail: c_avanti@staff.ubaya.ac.id)

Journal of Pharmaceutical Sciences, Vol. 102, 1734-1741 (2013)

() 2013 Wiley Periodicals, Inc. and the American Pharmacists Association
$\mathrm{Cys}^{1}-\mathrm{Tyr}^{2}-\mathrm{Ile}^{3}-\mathrm{Gln}^{4}-\mathrm{Asn}^{5}-\mathrm{Cys}^{6}$ with an N-terminal amino group, and of a linear Pro ${ }^{7}-\mathrm{Leu}^{8}-\mathrm{Gly}^{9}$ with a C-terminal amide. The secondary structure of the cyclic part is heterodetic with a disulfide linkage between two cysteine residues, namely $\mathrm{Cys}^{1}$ and $\mathrm{Cys}^{6}{ }^{6}{ }^{2}$

Unfortunately, a major problem in practice is that injectable oxytocin formulations become highly unstable when the storage temperature rises to $30^{\circ} \mathrm{C}$ or higher. ${ }^{3}$ Therefore, oxytocin should be refrigerated during storage and transportation, the so-called "cold chain," which cannot always be maintained, particularly in rural or tropical areas. ${ }^{4}$ Oxytocin can undergo degradation via deamidation, oxidation, or thiol exchange. ${ }^{5,6}$ In particular, the $\mathrm{Cys}^{1}-\mathrm{Cys}^{6}$ disulfide is susceptible to thiol exchange or oxidation promoted by oxygen, light, or transition metal ions. ${ }^{7-9}$ 


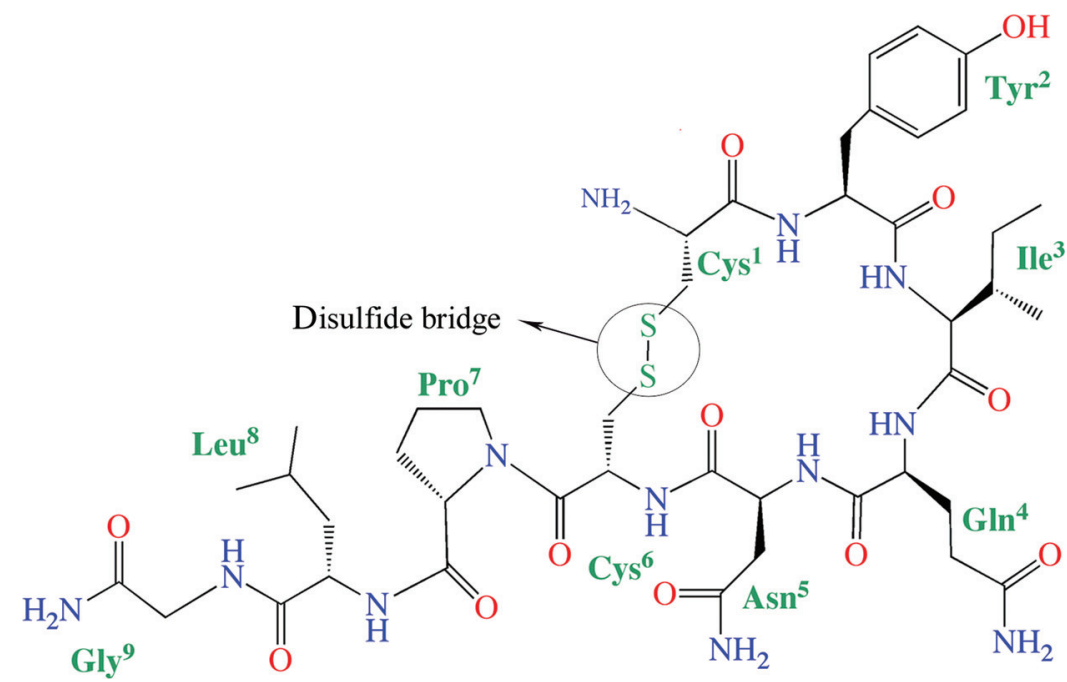

Figure 1. Oxytocin structure.

Several studies have been conducted to improve the stability of oxytocin formulations. ${ }^{5,6,10}$ Within this frame, we have previously demonstrated that combinations of divalent metal ions with citrate buffer greatly improve the stability of oxytocin in aqueous solution, whereas divalent metal ions added to nonbuffered aqueous oxytocin solutions have only limited stabilizing effects at $40^{\circ} \mathrm{C}$ or $55^{\circ} \mathrm{C} .{ }^{10}$ In a consecutive study, we have shown that formation of a complex of divalent metal ions and citrate with oxytocin leads to the suppression of cysteine-mediated intermolecular or intramolecular reactions, thus suppressing trisulfide/tetrasulfide and dimer formation. ${ }^{6}$

We have also observed that different types of buffers may lead to a different interaction between divalent metal ions and oxytocin, therefore having a different impact on oxytocin stability. For example, we demonstrated that addition of divalent metal ions to oxytocin solutions in either acetic or citric acid buffers results in different stabilization effects of the peptide in aqueous solution. ${ }^{10}$ Although $\mathrm{Ca}^{2+}, \mathrm{Mg}^{2+}$, and $\mathrm{Zn}^{2+}$ in combination with citrate buffer were successful in stabilizing oxytocin, no stabilizing effect was observed for the combination of the same divalent metal ions and acetate buffer. ${ }^{10}$ Acetic acid and citric acid are carboxylic acids with one and three carboxylate groups, respectively. Thus, the above-mentioned results suggest that a buffer with more than one carboxylate group is required for stabilizing the oxytocin-metal-buffer salt cluster. Indeed, preliminary experiments indicated that aspartate, a buffer containing two carboxylate and amine group, in combination with divalent metal ions stabilized oxytocin in solution (unpublished result). Therefore, the aim of the present study was to investigate the effects of divalent metal ions $\left(\mathrm{Ca}^{2+}, \mathrm{Mg}^{2+}\right.$, and $\left.\mathrm{Zn}^{2+}\right)$ on the stability of oxytocin in aspartate buffer in more detail. Aspar- tate was selected because it is a commonly used buffer in parenteral products approved by the US Food and Drug Administration for formulation purposes. ${ }^{11} \mathrm{It}$ was envisaged that the carboxylate groups of aspartate may establish different interactions and thereby differently affecting the peptide stability with respect to citric acid.

It should be noted that both the $\mathrm{pH}$ and concentration of metal ions in the formulation were found to be crucial in the effectiveness of oxytocin stabilization in citrate buffer. ${ }^{10,12}$ Thus, because the optimum stability of oxytocin was reported to be at $\mathrm{pH} 4.5,^{5}$ the peptide formulations were maintained at that $\mathrm{pH}$, whereas various divalent metal ion concentrations were tested. In addition, we have investigated the effect of divalent metal ions on the degradation profile of oxytocin in aspartate buffer by liquid chromatography-tandem mass spectrometry (LC-MS/MS). Finally, we performed isothermal titration calorimetry (ITC) experiments as a primary attempt to analyze the thermodynamics of the system at the molecular level.

\section{MATERIALS AND METHODS}

\section{Materials}

Oxytocin monoacetate powder (Diosynth, Oss, The Netherlands) was kindly provided by MSD, Oss, The Netherlands. L-Aspartic acid, magnesium chloride, and zinc chloride were purchased from Fluka, Steinheim, Germany. Calcium chloride was obtained from Riedel-de Haen, Seelze, Germany; and sodium hydroxide, sodium dihydrogen phosphate dihydrate, acetonitrile (supergradient grade), as well as formic acid were purchased from Merck, Darmstadt, Germany. 


\section{Methods}

\section{Formulation of Oxytocin Solution and Stability Study}

Oxytocin solution was formulated at a concentration of $0.1 \mathrm{mg} / \mathrm{mL}(0.094 \mathrm{mM})$ in $10 \mathrm{mM}$ aspartate buffer at $\mathrm{pH} 4.5$ (pH adjusted with sodium hydroxide) with different concentrations of divalent metal ions $\mathrm{Ca}^{2+}$, $\mathrm{Mg}^{2+}$, and $\mathrm{Zn}^{2+}$. All divalent metal ion solutions were prepared using their chloride salts at concentrations of $2,5,10$, and $50 \mathrm{mM}$. The concentration of oxytocin was determined using a UV spectrometer as described previously. ${ }^{10,13}$ After preparation, the solutions were stored in $6 \mathrm{R}$ glass type 1 vials for 4 weeks at either $4^{\circ} \mathrm{C}$ or $55^{\circ} \mathrm{C}$, and were protected from light. Some selected formulations were also stored for 5 days at $70^{\circ} \mathrm{C}$, and the samples were diluted 10 -fold with water for LC-MS/MS analysis. During the stability study, controlled $\mathrm{pH}$ levels in the samples were within $0.1 \mathrm{pH}$ units.

\section{Reversed-Phase High-Performance Liquid Chromatography}

Reversed-phase high-performance liquid chromatography was carried out according to the procedure described earlier. ${ }^{5,10}$ An Alltima C-18 RP column with $5 \mu \mathrm{m}$ particle size, inner diameter of $4.6 \mathrm{~mm}$, and length of $150 \mathrm{~mm}$ (Alltech, Ridderkerk, The Netherlands), a Waters (Millipore, Millford, MA) 680 automated gradient controller, two Waters 510 HPLC pumps, a Waters 717 plus autosampler, and a Waters 486 tunable absorbance UV detector were used. Samples of $20 \mu \mathrm{L}$ were injected, and the separation was carried out at a flow rate of $1.0 \mathrm{~mL} / \mathrm{min}$ and UV detection at $220 \mathrm{~nm}$. Samples were eluted using $15 \%$ (v/ v) acetonitrile in $65 \mathrm{mM}$ phosphate buffer, $\mathrm{pH} 5.0$, as solvent $\mathrm{A}$ and $60 \%(\mathrm{v} / \mathrm{v})$ acetonitrile in $65 \mathrm{mM}$ phosphate buffer, $\mathrm{pH}$ 5.0, as solvent B. The acetonitrile concentration was linearly increased from $15 \%$ at the beginning, to $20 \%$ at $10 \mathrm{~min}$, to $30 \%$ at $20 \mathrm{~min}$, and finally to $60 \%$ at $25 \mathrm{~min}$. The recovery of oxytocin is expressed as the percentage of initial amount.

\section{Size-Exclusion HPLC}

High-performance size-exclusion chromatography was performed according to the method previously reported ${ }^{5,10}$ A Superdex Peptide 10/300 GL column (GE Healthcare Inc., Brussels, Belgium) was used on an isocratic HPLC system with a Waters 510 pump, a Waters 717 plus autosampler, a Waters 474 scanning fluorescence detector, and a Waters 484 tunable absorbance detector (Waters, Milford, Massachusetts). Samples of $50 \mu \mathrm{L}$ were injected, and separation was performed at a flow rate of $1 \mathrm{~mL} / \mathrm{min}$. Chromatograms were obtained using fluorescence detection at excitation wavelength of $274 \mathrm{~nm}$ and emission wavelength of $310 \mathrm{~nm}$. The mobile phase consisted of $30 \%$ acetonitrile and $70 \% 0.04 \mathrm{M}$ formic acid. The recovery of monomeric oxytocin is expressed as the percentage of initial amount.

\section{Liquid Chromatography-Tandem Mass Spectrometry}

The LC-MS/MS system was set up according to the method described earlier. ${ }^{5,10}$ A Shimadzu (Kyoto, Japan) LC system equipped with LC-20AD gradient pumps and a SIL-20AC autosampler was used. The chromatographic separation was carried out on an Alltima C18 column (internal diameter $2.1 \mathrm{~mm}$, length $150 \mathrm{~mm}$, particle size $5 \mu \mathrm{m}$; Grace Davison Discovery Sciences). The gradient mobile-phase composition was a mixture of solvent A consisting of $95 \%$ water and 5\% acetonitrile and solvent B consisting of $5 \%$ water and $95 \%$ acetonitrile, both containing $0.05 \%$ $(\mathrm{v} / \mathrm{v})$ acetic acid and $10 \mathrm{mM}$ ammonium acetate. Elution was performed by a linear gradient from 5\% to $60 \%$ of the solvent B in $30 \mathrm{~min}$, followed by an increase to $90 \%$ solvent B in $1 \mathrm{~min}$, where it was kept for $4 \mathrm{~min}$, after which it returned to the starting conditions. The flow rate was $0.2 \mathrm{~mL} / \mathrm{min}$. The UV signal was recorded at $220 \mathrm{~nm}$. The injection volume was $50 \mu \mathrm{L}$.

The HPLC system was coupled to an API 3000 triple-quadrupole mass spectrometer (Applied Biosystems/MDS Sciex) via a turbo ion spray source. The ionization was performed by electrospray in the positive mode. Full scan spectra were recorded at a scan rate of $2 \mathrm{~s}$ from $\mathrm{m} / z 500$ to 1300 and a step size of $0.2 \mathrm{amu}$ with a declustering potential (DP) of $40 \mathrm{~V}$ and a focusing potential (FP) of $250 \mathrm{~V}$. Product ion scans were acquired in specified time windows with a DP of $60 \mathrm{~V}$, a FP of $300 \mathrm{~V}$, a collision energy of $40 \mathrm{~V}$, and a collision cell exit potential of $20 \mathrm{~V}$. Data acquisition and processing were performed using Analyst version 1.5 software (Applied Biosystems/MDS Sciex).

Liquid chromatography-tandem mass spectrometry was used to identify the oxytocin degradation products observed by RP-HPLC with UV detection. The analyses were carried out on each of the major degradation peaks for oxytocin in aspartate buffer formulation without divalent metal salts as well as by LC-MS for the formulation with divalent metal salts.

\section{Isothermal Titration Calorimetry}

Microcalorimetric titrations of divalent metal ions to oxytocin in aspartate buffer were performed by using a MicroCal ITC $_{200}$ microcalorimeter (Northampton, Massachusetts) as described previously. ${ }^{10} \mathrm{~A}$ solution of $30 \mu \mathrm{L}$ of $125 \mathrm{mM}$ divalent metal chloride (calcium, magnesium, or zinc chloride) in $10 \mathrm{mM}$ aspartate buffer, $\mathrm{pH} 4.5$, was placed in the syringe, whereas $300 \mu \mathrm{L}$ of $5 \mathrm{mM}$ oxytocin in $10 \mathrm{mM}$ of aspartate buffer, $\mathrm{pH}$ 4.5, was placed in the sample cell. The reference cell contained $300 \mu \mathrm{L}$ of aspartate buffer. Experiments were performed at $55^{\circ} \mathrm{C}$. The effective heat of the peptide-metal ion interaction upon each titration step was corrected for dilution and mixing effects, as 
measured by titrating the divalent metal ion solution into the buffer and by titrating the buffer into the oxytocin solution (reference measurement). To investigate the possibility of oxytocin or metal ion binding to the buffer components, control experiments were performed in water. The heats of bimolecular interactions were obtained by integrating the peak following each injection. All measurements were performed in triplicate. ITC data were analyzed by using the ITC nonlinear curve fitting functions for one or two binding sites from Origin 7.0 software (MicroCal Software, Inc.).

\section{RESULTS}

\section{The Effect of Divalent Metal Ions on Oxytocin Stability in Aspartate Buffer Solution}

To investigate the stability of oxytocin in the aspartate-buffered solutions in the presence of divalent metal ions, oxytocin formulation in $10 \mathrm{mM}$ aspartate buffer ( $\mathrm{pH} 4.5)$ with various concentrations of divalent metal ions were prepared. Oxytocin is commonly formulated at a concentration of about $0.01 \mathrm{mg} /$ $\mathrm{mL}$, which is 10 times lower than the concentration used in this study. The higher concentration was chosen to have higher peak intensities of the degradation products in the chromatograms (RP-HPLC and HP-SEC). Oxytocin recovery and the presence of oxytocin monomer were determined by RP-HPLC and HP-SEC, respectively, after 4 weeks of storage at $4^{\circ} \mathrm{C}$ and $55^{\circ} \mathrm{C}$. The results are shown in Figure 2. After 4 weeks of storage at $4^{\circ} \mathrm{C}$, oxytocin remained stable in all formulations. Instead, after 4 weeks of storage at $55^{\circ} \mathrm{C}$, oxytocin stability increased with increasing divalent metal ions concentration. $\mathrm{Ca}^{2+}$ and $\mathrm{Mg}^{2+}$ had similar effects on improving the oxytocin stability; the recovery of oxytocin as well as the remaining percentage of oxytocin monomer increased up to $45 \%$ in the presence of $50 \mathrm{mM} \mathrm{Mg}^{2+}$, and up to $35 \%$ in the presence of $50 \mathrm{mM} \mathrm{Ca}{ }^{2+}$. Notably, $\mathrm{Zn}^{2+}$ was much more effective in stabilizing oxytocin; the recovery of oxytocin and the remaining percentage of oxytocin monomer increased up to $35 \%$ at a concentration of $2 \mathrm{mM} \mathrm{Zn}^{2+}$ (i.e., to a comparable extent as $50 \mathrm{mM} \mathrm{Ca}^{2+}$ or $\mathrm{Mg}^{2+}$ ) and to about $75 \%$ at a concen-

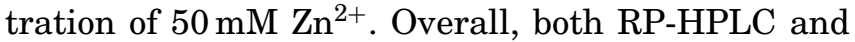
HP-SEC showed that $\mathrm{Zn}^{2+}$ has superior stabilizing effects in aspartate buffer compared with $\mathrm{Ca}^{2+}$ and $\mathrm{Mg}^{2+}$.

\section{The Effect of Divalent Metal Ions on the Degradation Profile of Oxytocin in Aspartate Buffer}

To assign the degradation products of oxytocin in the formulations, oxytocin in $10 \mathrm{mM}$ aspartate buffer $(\mathrm{pH} 4.5)$ in the absence and presence of $10 \mathrm{mM}$ divalent metal ions was analyzed by LC-MS/MS after a
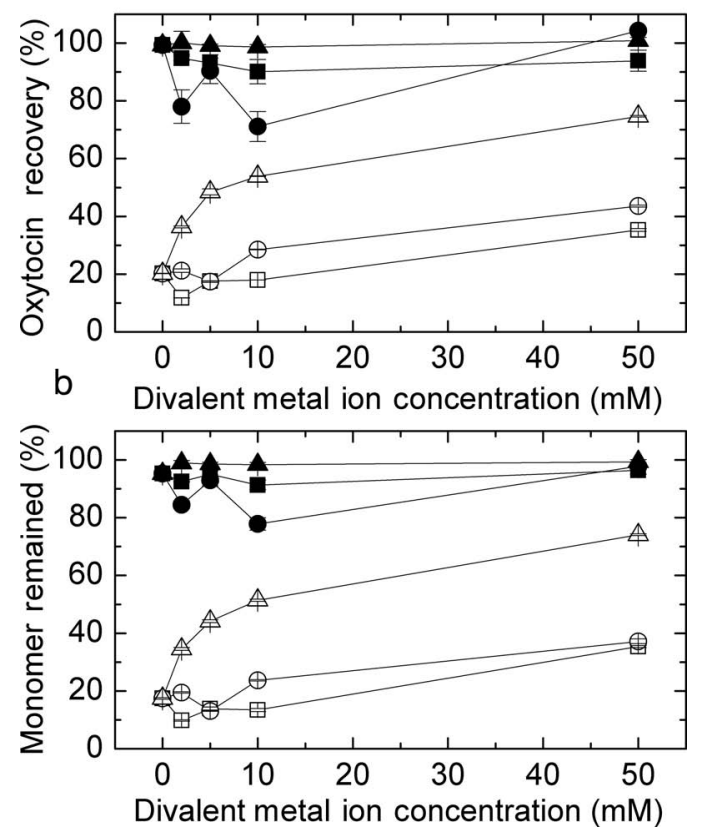

Figure 2. Effects of $\mathrm{Ca}^{2+}$ (squares), $\mathrm{Mg}^{2+}$ (circles), and $\mathrm{Zn}^{2+}$ (triangles) concentration on the recovery of oxytocin in $10 \mathrm{mM}$ aspartate buffer, $\mathrm{pH} 4.5$, after 4 weeks of storage at either $4^{\circ} \mathrm{C}$ (solid symbols) or $55^{\circ} \mathrm{C}$ (open symbols). (a) Oxytocin recovery determined by RP-HPLC. (b) Oxytocin monomer remaining as determined by HP-SEC. The results are depicted as averages of three independent measurements \pm SD.

incubation of the samples at $70^{\circ} \mathrm{C}$ for 5 days to ensure the formation of sufficient amounts of degradation products to be analyzed properly. MS/MS analysis was applied to confirm the identification of the most intense peaks, and degradation products were assigned following our previous reports..$^{5,6,14}$ Figure $3 \mathrm{a}$ shows the total ion current of mass spectra in the $\mathrm{m} / \mathrm{z}$ range between 900 and 1200 for the formulation of oxytocin without divalent metal ions (solid line), and with $10 \mathrm{mM} \mathrm{Zn}^{2+}$ (dashed line). Spectra of the formulations with calcium and magnesium ions are shown in the supplementary material. Nine peaks can be observed in the MS profile of the formulation without divalent metal ions after thermal stress. These nine revealed 10 molecular species in the LC-MS contour plot (Fig. 3b). The protonated molecular ion of unmodified oxytocin was found at a retention time of $12.8 \mathrm{~min}$ with $\mathrm{m} / \mathrm{z}$ of 1007.4 . A peak at a retention time of $14.5 \mathrm{~min}$ with $\mathrm{m} / \mathrm{z} 1066.6$, corresponding to oxytocin acetate (ammoniated), appeared in the LC-MS of both stressed and unstressed oxytocin formulations. Most likely, oxytocin acetate was formed during synthesis as the oxytocin was supplied as a monoacetate salt. Complete assignment of the degradation products is listed in Table 1 . At retention time of 13.7 and $15.0 \mathrm{~min}$ trisulfide and tetrasulfide form 

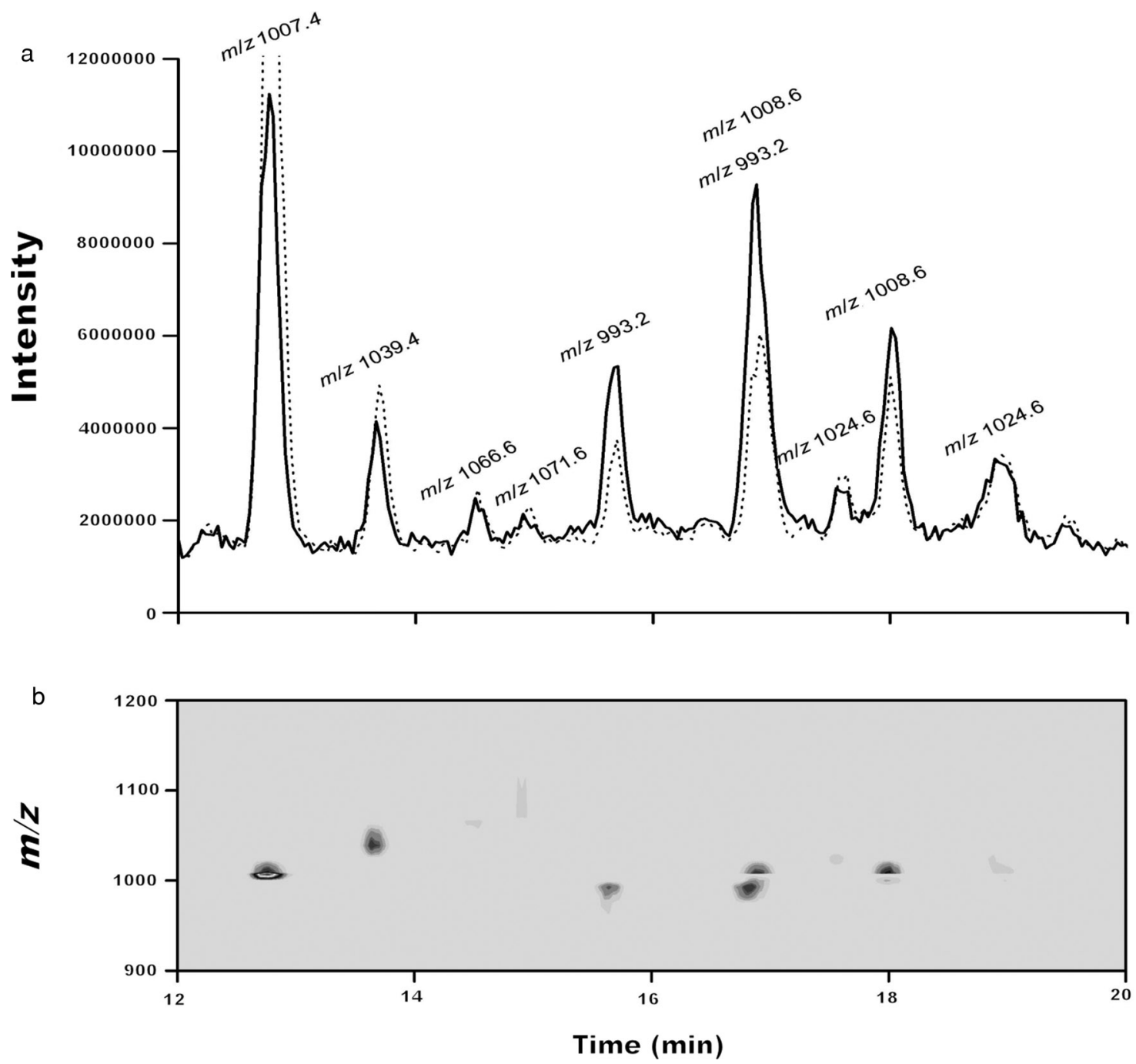

Figure 3. (a) The total ion current and (b) contour plot of mass spectra $(\mathrm{m} / \mathrm{z} 900-1200)$ of oxytocin and its degradation products in $10 \mathrm{mM}$ aspartate buffer after 5 days of storage at $70^{\circ} \mathrm{C}$

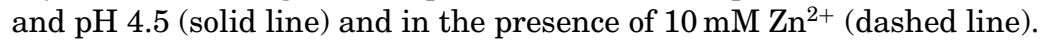

degradation products were identified from the $\mathrm{m} / \mathrm{z}$ 1039.6 and 1071.6 peaks, respectively (see supplementary material for the structures of trisulfide and tetrasulfide oxytocin species). Other peaks (i.e., dimers 1-6 in Table 1) are interpreted as various forms of disulfide or thioether-linked oxytocin dimers as described previously. ${ }^{6}$

Addition of divalent metal salts in the formulation with the aspartate buffer did not result in any additional degradation products compared with samples without metal salts (see dashed line in Fig. 3a for the formulation containing $10 \mathrm{mM} \mathrm{Zn}^{2+}$ ). Conversely, as expected from the RP-HPLC and HP-SEC data, it resulted in a significant reduction of the major degradation peaks. The intensity of each degradation product from each stressed formulation of oxytocin in aspartate buffer in combination with $\mathrm{Ca}^{2+}, \mathrm{Mg}^{2+}$, and $\mathrm{Zn}^{2+}$ was recorded. In Table 1, the relative intensities in percentage of the peak area of each degradation prod- uct in the presence of divalent metal ions with respect to the same formulations without divalent metal ions are listed. Addition of $\mathrm{Ca}^{2+}$ and $\mathrm{Mg}^{2+}$ reduced the formation of dimers 1 and 2 of about $30 \%$, an effect that was even more pronounced in the presence of $\mathrm{Zn}^{2+}$, that is, $53 \%$ and $60 \%$ reduction for dimers 1 and 2 , respectively.

$\mathrm{Zn}^{2+}$ was the most efficient divalent metal ion in suppressing the total amount of the degradation products of oxytocin in aspartate buffer. In fact, in contrast to $\mathrm{Ca}^{2+}$ and $\mathrm{Mg}^{2+}, \mathrm{Zn}^{2+}$ also reduced the formation of other dimers: dimer 3 was reduced by $14 \%$, and dimer 5 was reduced by $30 \%$. However, an increase in the formation of trisulfide and tetrasulfide species was also observed. The signal intensity of the tetrasulfide form $(\mathrm{m} / z$ 1071.6, retention time $15.0 \mathrm{~min})$ is very low compared with that of the dimers, and therefore peak integration was less accurate. We have no explanation for the increased intensity of the 
Table 1. Effect of Divalent Metal Ions on the Intensity of Oxytocin in Aspartate-Buffered Solution

\begin{tabular}{|c|c|c|c|c|c|}
\hline \multirow[b]{2}{*}{ Assignment } & \multirow[b]{2}{*}{ Retention Time (min) } & \multirow[b]{2}{*}{$m / z$} & \multicolumn{3}{|c|}{ Relative Peak Intensity (\%) of Oxytocin ${ }^{a}$} \\
\hline & & & $\mathrm{Ca}^{2+}$ & $\mathrm{Mg}^{2+}$ & $\mathrm{Zn}^{2+}$ \\
\hline Oxytocin trisulfide & 13.7 & 1039.4 & $111 \pm 4$ & $101 \pm 8$ & $146 \pm 5$ \\
\hline Oxytocin tetrasulfide & 15.0 & 1071.6 & $135 \pm 13$ & $114 \pm 10$ & $187 \pm 12$ \\
\hline Dimer 1 & 15.7 & $993.2^{b}$ & $68 \pm 3$ & $68 \pm 2$ & $47 \pm 0$ \\
\hline Dimer 2 & 16.7 & $993.2^{b}$ & $69 \pm 3$ & $76 \pm 2$ & $39 \pm 2$ \\
\hline Dimer 3 & 16.9 & 1008.6 & $115 \pm 4$ & $111 \pm 2$ & $86 \pm 2$ \\
\hline Dimer 4 & 17.6 & $1024.6^{b}$ & $147 \pm 19$ & $135 \pm 3$ & $127 \pm 5$ \\
\hline Dimer 5 & 18.0 & 1008.6 & $111 \pm 2$ & $111 \pm 1$ & $71 \pm 3$ \\
\hline Dimer 6 & 18.9 & $1024.6^{b}$ & $152 \pm 8$ & $144 \pm 3$ & $115 \pm 18$ \\
\hline
\end{tabular}

Relative peak intensity is expressed with respect to that of the same product in the absence of divalent metal ions.

${ }^{a}$ Aspartate buffer solution with $10 \mathrm{mM}$ of the indicated divalent metal ion.

${ }^{b}$ Ammoniated.

trisulfide form $(\mathrm{m} / z$ 1039.4, retention time $13.7 \mathrm{~min})$ in the presence of $\mathrm{Zn}^{2+}$ because the mechanism of trisulfide and tetrasulfide formation is unclear.

After 5 days of storage at $70^{\circ} \mathrm{C}$, oxytocin formulated in aspartate buffer without divalent metal ions was the most degraded of all formulations tested, and only approximately $20 \%$ oxytocin could be recovered (Fig. 4). Addition of $10 \mathrm{mM} \mathrm{Ca}^{2+}$ and $\mathrm{Mg}^{2+}$ did not markedly improve the peptide recovery, which is in agreement with the results of the stability study at $55^{\circ} \mathrm{C}$. However, when $\mathrm{Zn}^{2+}$ was added, the degradation was reduced and a recovery of about $45 \%$ oxytocin was found.

\section{Interaction of Oxytocin and Divalent Metal lons in Aspartate Buffer}

The interaction of oxytocin with divalent metal ions was investigated by ITC at a temperature of $55^{\circ} \mathrm{C}$. Figure 5 shows the exothermic $\left(\Delta H_{\text {obs }}\right)$ events when $\mathrm{Ca}^{2+}$ or $\mathrm{Mg}^{2+}$ was titrated into a solution of oxytocin in $10 \mathrm{mM}$ aspartate buffer. The effects were very small (not more than $0.05 \mathrm{kcal} / \mathrm{mol}$ of injectant) and only slightly different from the corresponding reference measurements. On the contrary, when $\mathrm{Zn}^{2+}$ was titrated into oxytocin in aspartate buffer, a strong endothermic reaction was observed and the heat effects upon the titration reached more than $0.5 \mathrm{kcal} / \mathrm{mol}$ for the first injection. The shape of the titration curve for the $\mathrm{Zn}^{2+}$-oxytocin in aspartate is indicative of a binding reaction. Using the analysis model with two distinct types of binding sites, the binding constants $K_{\mathrm{a}}$ at $55^{\circ} \mathrm{C}$ for $\mathrm{Zn}^{2+}$ - oxytocin interaction are $6.2 \pm 1.0 \times$ $10^{3}$ and $72 \pm 17 \mathrm{M}^{-1}$, respectively. Thus, although we did not elucidate the binding mechanism in full details, the ITC results clearly reveal that the only system that shows substantial thermodynamics interactions has the most pronounced effect on the stability of the aqueous oxytocin formulations we evaluated in this study.

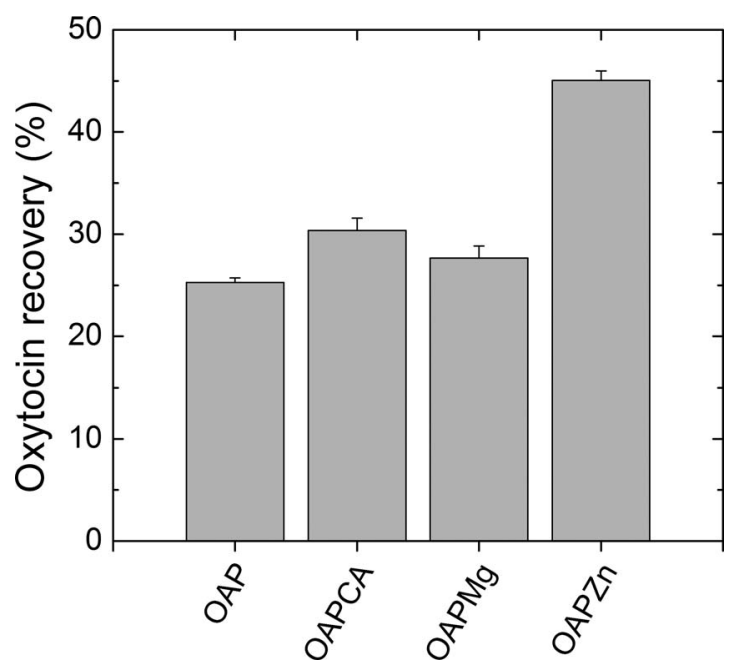

Figure 4. Recovery of oxytocin in the absence (OAP) and presence of $10 \mathrm{mM} \mathrm{Ca}^{2+}$ (OAPCa), $\mathrm{Mg}^{2+}\left(\mathrm{OAPMg}\right.$ ), and $\mathrm{Zn}^{2+}$ (OAPZn) in $10 \mathrm{mM}$ aspartate-buffered solution at $\mathrm{pH} 4.5$ under stressed condition at a temperature of $70^{\circ} \mathrm{C}$ for 5 days. Oxytocin recovery determined by LC-MS. The results are depicted as averages of three independent measurements \pm SD.

\section{DISCUSSION}

In a previous study, we found that oxytocin can be stabilized by a combination of divalent metal ions and citrate buffer at $\mathrm{pH}$ 4.5. Divalent metal ions in combination with citrate buffer suppressed intermolecular reactions in the disulfide bridge region presumably by forming a complex in that region. At a concentration of $50 \mathrm{mM}$, there were no significant differences observed among the three tested divalent metal ions, $\mathrm{Ca}^{2+}, \mathrm{Mg}^{2+}$, and $\mathrm{Zn}^{2+} .{ }^{10}$ Our present study indicates that formulations with a combination of divalent metal ions and aspartate buffer behave differently in improving oxytocin stability in aqueous solution. In fact, we have shown that in aspartate buffer, only the addition of $50 \mathrm{mM} \mathrm{Zn}^{2+}$ results in a comparable stabilizing effect on oxytocin as citrate with $\mathrm{Ca}^{2+}, \mathrm{Mg}^{2+}$, and $\mathrm{Zn}^{2+} .{ }^{10}$ The LC-MS/MS results show 


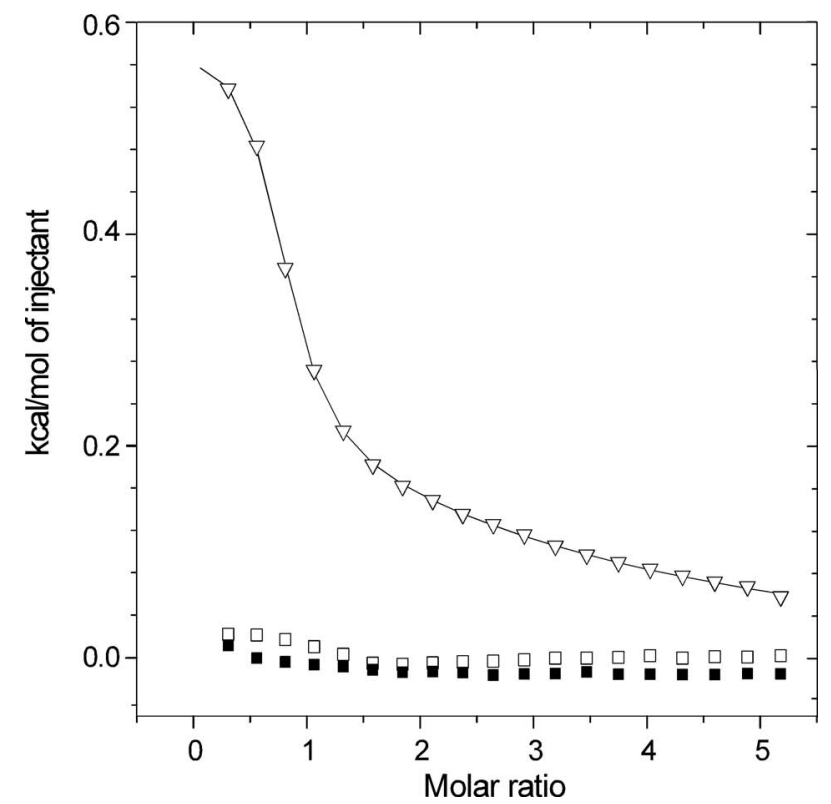

Figure 5. Least squares fit of the data from calorimetric titration profiles of aliquots of $125 \mathrm{mM}$ divalent metal ions: $\mathrm{Ca}^{2+}$ (solid square), $\mathrm{Mg}^{2+}$ (open square), and $\mathrm{Zn}^{2+}$ (open triangle) into $5 \mathrm{mM}$ oxytocin in $10 \mathrm{mM}$ aspartate buffer ( $\mathrm{pH}$ 4.5). The heat absorbed per mole of titrant is plotted versus the ratio of the total concentration of divalent metal ions to the total concentration of oxytocin.

that in particular the formation of oxytocin dimers is strongly reduced by the presence of $\mathrm{Zn}^{2+}$ in aspartate, whereas it is only moderately affected by $\mathrm{Ca}^{2+}$ and $\mathrm{Mg}^{2+}$. Our previous study showed that all the dimers were produced from the thiol exchange in the disulfide bridge. ${ }^{6}$ Thus, it appears that the combination of $\mathrm{Zn}^{2+}$ and aspartate was able to protect the disulfide Cys ${ }^{1,6}$ bridge of oxytocin, whereas the combination of $\mathrm{Ca}^{2+}$ or $\mathrm{Mg}^{2+}$ does not. In line with these results, ITC data demonstrate that in the presence of aspartate, only $\mathrm{Zn}^{2+}$, among the tested divalent metal ions, was able to strongly interact with oxytocin.

The whole assembly of oxytocin-divalent metal ion buffer is a complex process, wherein individual interactions between components may be additionally probed by ITC (see Supplementary Material S5 and S6). Apparently, the individual interactions between oxytocin and the divalent metal ions cannot guarantee the complex stability when the buffering component is added. One example here is $\mathrm{Ca}^{2+}$ : it interacts strongly with oxytocin in water, and also forms a complex with the aspartate in solution, but the trivalent OT- $\mathrm{Ca}^{2+}$-aspartate complex formation was not detected, and oxytocin remained unstable in the corresponding formulation. In contrast, $\mathrm{Zn}^{2+}$ demonstrated endothermic binding to the aspartate, although not to oxytocin alone. Oxytocin binding was induced in the presence of aspartate buffer. It also im- plies that initial $\mathrm{Zn}^{2+}-\mathrm{Asp}$ complexation is required to acquire the affinity to OT.

The observed stabilization effects might be ascribed to the formation of divalent metal ion adducts to oxytocin, which has been reported in various publications. ${ }^{15-17}$ A compact oxytocin-metal-octahedral complex is formed by the coordination of the metal ions and the oxygen atoms of the backbone carbonyl groups of oxytocin ${ }^{15,18,19}$ with the divalent metal ions, $\mathrm{Ca}^{2+}, \mathrm{Mg}^{2+}$, and $\mathrm{Zn}^{2+}$, positioned within the oxytocin ring. ${ }^{20,21}$ It is well known that the binding affinity of oxytocin for $\mathrm{Mg}^{2+}$ is lower than in the case of $\mathrm{Ca}^{2+}$, and by far lower than in the case of $\mathrm{Zn}^{2+}{ }^{15,18,19}$ Indeed, $\mathrm{Zn}^{2+}$ very effectively coordinate with oxytocin and strongly affect its conformation in a physiological environment. ${ }^{19}$ Therefore, the superior stabilizing effects of $\mathrm{Zn}^{2+}$ with respect to $\mathrm{Ca}^{2+}$ and $\mathrm{Mg}^{2+}$ might be because of the higher stability of the oxytocin $-\mathrm{Zn}^{2+}$ adduct.

In addition, our results show that the type of buffer also plays an important role on the stability of the peptide. At a $\mathrm{pH}$ of 4.5 , citrate has one carboxylate ion $\left(-\mathrm{COO}^{-}\right)$in alpha position and other two carboxylate groups that can contribute to the coordination of a metal or to binding to oxytocin itself. At the same $\mathrm{pH}$ of 4.5 , aspartate has only two carboxylate ions that could act as electron donors toward a metal ion or oxytocin. This difference of available electron donor groups between the two buffers might influence the oxytocin-metal adduct formation, as well as its stabilization. The lack of an additional electron donor oxygen moiety in aspartate is likely to discriminate the binding of $\mathrm{Ca}^{2+}$ or $\mathrm{Mg}^{2+}$ with respect to $\mathrm{Zn}^{2+}$, as suggested by the ITC results, which did not show any significant interactions between oxytocin and $\mathrm{Ca}^{2+}$ or $\mathrm{Mg}^{2+}$ in aspartate buffer.

\section{CONCLUSIONS}

Our study clearly shows that the stability of oxytocin in the aspartate-buffered solution is strongly improved in the presence of $\mathrm{Zn}^{2+}$, and the stabilization effect is correlated with the strength of interaction between oxytocin and divalent metal ions. The improved stability of oxytocin can be ascribed to binding of $\mathrm{Zn}^{2+}$ to the peptide facilitated by aspartate by which the intermolecular degradation reactions near the $\mathrm{Cys}^{1,6}$ disulfide bridge are suppressed.

\section{ACKNOWLEDGMENTS}

The authors want to thank MSD, Oss, The Netherlands for providing oxytocin for the study. This research was performed within the framework of the Dutch Top Institute Pharma (project number D6-202) and Rosalind Franklin fellowship funding for Angela Casini. 


\section{REFERENCES}

1. International Confederation of Midwives. 2012. International Confederation of Midwives. International Federation of Gynaecology and Obstetrics. Joint statement management of the third stage of labour to prevent post-partum haemorrhage. Accessed at: http://www internationalmidwives org/ Whatwedo/ Programmes/POPPHI/PostPartumHaemorrhage/tabid/339/ Default.aspx 2012, accessed on January 4, 2012.

2. Ohno A, Kawasaki N, Fukuhara K, Okuda H, Yamaguchi T. 2010. Complete NMR analysis of oxytocin in phosphate buffer. Magn Reson Chem 48:168-172.

3. Gard JW, Alexander JM, Bawdon RE, Albrecht JT. 2002. Oxytocin preparation stability in several common obstetric intravenous solutions. Am J Obstet Gynecol 186:496-498.

4. Hogerzeil HV, Walker GJA, De Goeje MJ. 1993. Stability of injectable ocytocics in tropical climates (WHO/DAP/93.6). Geneva, Switzerland: World Health Organization.

5. Hawe A, Poole R, Romeijn S, Kasper P, van der Heijden R, Jiskoot W. 2009. Towards heat-stable oxytocin formulations: Analysis of degradation kinetics and identification of degradation products. Pharm Res 26:1679-1688.

6. Avanti C, Permentier HP, Dam AV, Poole R, Jiskoot W, Frijlink HW, Hinrichs WLJ. 2012. A new strategy to stabilize oxytocin in aqueous solutions: II. Suppression of cysteine-mediated intermolecular reactions by a combination of divalent metal ions and citrate. Mol Pharm 9:554-562.

7. Benesch RE, Benesch R. 1958. The mechanism of disulfide interchange in acid solution; role of sulfenium ions. J Am Chem Soc 80:1666-1669.

8. Mozziconacci O, Schoneich C. 2012. Photodegradation of oxytocin and thermal stability of photoproducts. J Pharm Sci 101:3331-3346.

9. Manning MC, Chou DK, Murphy BM, Payne RW, Katayama DS. 2010. Stability of protein pharmaceuticals: An update. Pharm Res 27:544-575.

10. Avanti C, Amorij JP, Setyaningsih D, Hawe A, Jiskoot W, Visser J, Kedrov A, Driessen AJ, Hinrichs WL, Frijlink HW. 2011. A new strategy to stabilize oxytocin in aqueous solutions:
I. The effects of divalent metal ions and citrate buffer. AAPS J 13:284-290.

11. Jurgens P, Panteliadis C, Fondalinski G. 1982. Total parenteral nutrition of premature infants: Metabolic effects of an exogenous supply of L-aspartic acid and L-glutamic acid. Z Ernahrungswiss 21:225-245.

12. Wakankar AA, Borchardt RT. 2006. Formulation considerations for proteins susceptible to asparagine deamidation and aspartate isomerization. J Pharm Sci 95:2321-2336.

13. Gill SC, von Hippel PH. 1989. Calculation of protein extinction coefficients from amino acid sequence data. Anal Biochem 182:319-326

14. Poole RA, Kasper PT, Jiskoot W. 2011. Formation of amideand imide-linked degradation products between the peptide drug oxytocin and citrate in citrate-buffered formulations. J Pharm Sci 100:3018-3022.

15. Ananthanarayanan VS, Brimble KS. 1996. Interaction of oxytocin with $\mathrm{Ca}^{2+}: \mathrm{I}$. CD and fluorescence spectral characterization and comparison with vasopressin. Biopolymers 40:433-443.

16. Einspahr H, Bugg CE. 1981. The geometry of calcium-carboxylate interactions in crystalline complexes. Acta Cryst B37:1044-1052.

17. Glusker JP, Katz AK, Bock CW. 1999. Metal ions in biological systems. Rigaku J 16:8-19.

18. Ananthanarayanan VS, Belciug MP, Zhorov BS. 1996. Interaction of oxytocin with $\mathrm{Ca}^{2+}$ : II. Proton magnetic resonance and molecular modeling studies of conformations of the hormone and its $\mathrm{Ca}^{2+}$ complex. Biopolym 40:445-464.

19. Liu D, Seuthe AB, Ehrler OT, Zhang X, Wyttenbach T, Hsu JF, Bowers MT. 2005. Oxytocin-receptor binding: Why divalent metals are essential. J Am Chem Soc 127:20242025.

20. Holm RH, Kennepohl P, Solomon EI. 1996. Structural and functional aspects of metal sites in biology. Chem Rev 96:2239-2314.

21. Katz AK, Glusker JP, Beebe SA, Bock CW. 1996. Calcium ion coordination: A comparison with that of beryllium, magnesium, and zinc. J Am Chem Soc 118:5752-5763. 